EPJ Web of Conferences 33, 05007 (2012)

DOI: $10.1051 /$ epjconf/20123305007

(C) Owned by the authors, published by EDP Sciences, 2012

\title{
Detailed dynamic heat transfer in thick brick walls typical of Lille Metropolis
}

\author{
E. Sassine $e^{1,2, a}$, Z. Younsi ${ }^{1,2}$, Y. Chérif ${ }^{1,2}$, and E. Antczak ${ }^{2}$ \\ ${ }^{1}$ HEI (Hautes Etudes d'Ingénieur), Catholic University, 59000 Lille, France \\ ${ }^{2}$ LGCgE (Laboratoire de Génie Civil et géo Environnement) 62000 Béthune, France
}

\begin{abstract}
The study of thermal transfer in old houses massive walls offers a big interest permitting the understanding of their specificities and the choice of a suitable material for their eventual insulation. We propose to study the thermal transfer in massive brick walls that characterize the Northern Europe old houses. To do so, we will begin by defining the thermal transfer mode: we proved that the transfer mode can be reduced to a unidirectional transfer. Then, an experimental wall is built and submitted to two different solicitation types (constant temperature in steady state mode and sinusoidal temperature) through a wooden insulated box containing a radiator. The interest of these solicitations is to determine the thermal properties of the wall: the steady-state regime permits to determine the thermal resistances of the system when the harmonic regime permits to determine the thermal capacities of the system.
\end{abstract}

\section{Introduction}

Old brick walls are one of the main characteristics of Northern European old buildings where they dominate in almost all the cities there and particularly in Lille, a city in the North of France where old individual houses constructed before 1948 constitute about the half of the existing houses [1] and are divided in three main categories: the "courée" houses, the town houses and the bourgeois houses $[2,3]$. The majority of these houses need a rehabilitation to be adaptable with the contemporary requirements of comfort; however a specific attention should be done to the thermal transfer in the thermal transfer in the walls on these old houses in order to understand their thermal behavior before any intervention $[4,5]$. In this paper we determine the thermal behavior of the wall and its thermal properties in two main solicitation modes: the steady state mode (time scale $\sim 1 \mathrm{~h}$ ) and the harmonic mode (time scale $\sim 1$ day).

\section{The thermal transfer mode}

The wall studied is the most common exterior wall presented in the north region of France. It is a 34 $\mathrm{cm}$ massive wall constituted of bricks associated with mortar as shown in figure 1.

\footnotetext{
a e-mail : emilio.sassine@hei.fr
} 
Using a constant difference of temperature equal to $20^{\circ} \mathrm{C}$ and neglecting inside and outside resistance, the $3 \mathrm{D}$ model thermal resistance can be deduced by:

$$
R=\frac{\Delta T}{q}=\frac{20}{q}
$$

Using the electrical analogy, the overall surface thermal resistance of the wall can be expressed by:

$$
R \approx \frac{142.79 \lambda_{b}{ }^{2}+255.55 \lambda_{m}{ }^{2}+5051.63 \lambda_{b} \cdot \lambda_{m}}{143.32 \lambda_{m}{ }^{3}+3541.24 \lambda_{m}{ }^{2} \lambda_{b}+12346.73 . \lambda_{m} \lambda_{b}{ }^{2}}
$$

$\lambda_{b}$ represents thermal conductivity of the brick and $\lambda_{\mathrm{m}}$ the thermal conductivity of the mortar (see figure 2).
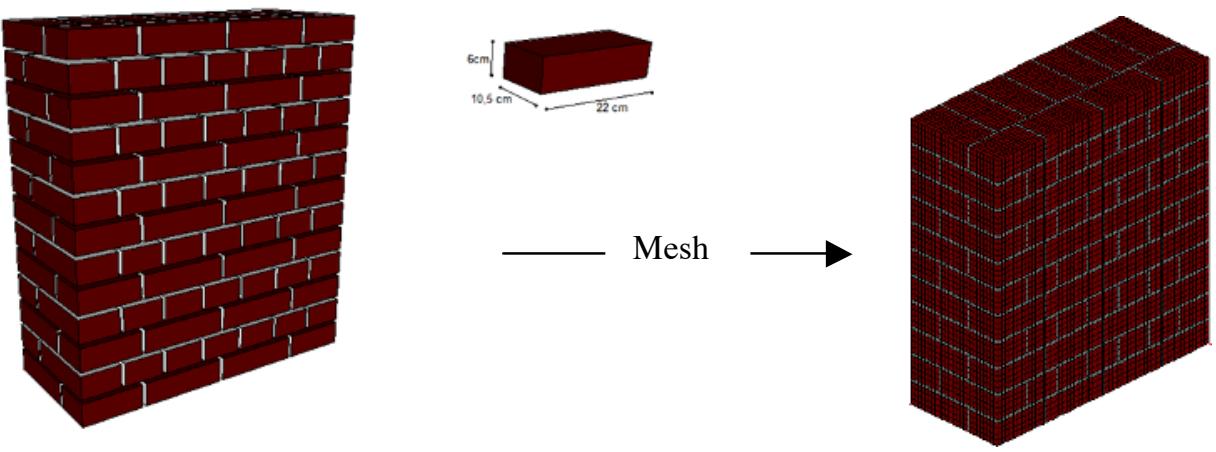

Fig. 1. Wall configuration
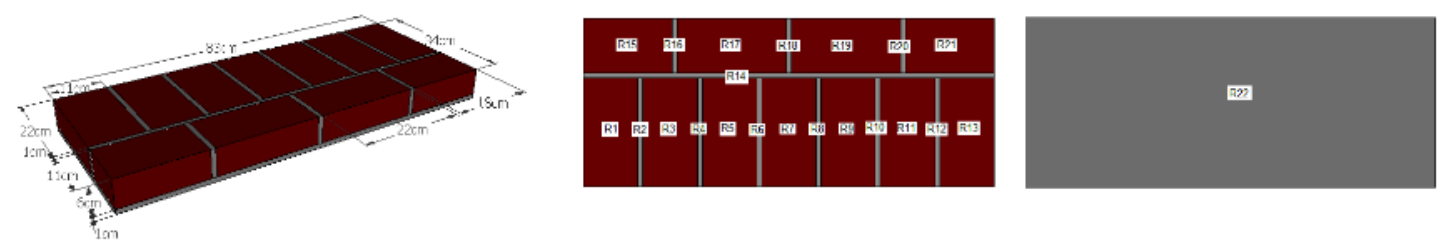

Fig. 2. Decomposition of the repeating unit into thermal resistance units in series and parallel

The heterogeneous wall made of brick and mortar can be assimilated to a uniform monolayer wall which characteristics can be evaluated as follow:

$$
\begin{gathered}
\lambda_{e q}=\frac{e}{R_{e q}} \\
(\rho c)_{e q}=\frac{(\rho c)_{\text {brick }} * V_{\text {brick }}+(\rho c)_{\text {mortar }} * V_{\text {mortar }}}{V_{\text {total }}}
\end{gathered}
$$


To compare the 1D and 3D heat transfer we will base our comparison on brick and mortar thermal properties found in the bibliography [6]; however the validity of the unidirectional approximation does not depend on the choice of these values.

Table 1. Material properties for numerical application

\begin{tabular}{|c|c|c|c|}
\hline Material & $\begin{array}{c}\text { Thermal conductivity } \\
{[\mathbf{W} / \mathbf{m} . \mathbf{K}]}\end{array}$ & Density $[\mathbf{k g} / \mathbf{m} 3]$ & $\begin{array}{c}\text { Thermal capacity } \\
{[\mathbf{J} / \mathbf{k g} . \mathbf{K}]}\end{array}$ \\
\hline Brick & 0.85 & 2000 & 1000 \\
\hline Mortar & 1.35 & 1600 & 1000 \\
\hline
\end{tabular}

The results show that for the considered thermal properties the 3D Heat Transfer Model the thermal resistance using Eq. (1) is $0.358 \mathrm{~m}^{2} \mathrm{~K} / \mathrm{W}$, while Eq. (2) gives a value of $0.356 \mathrm{~m}^{2} . \mathrm{K} / \mathrm{W}$ with a difference of almost $0.78 \%$.

In order to understand the thermal behavior of the wall in dynamic conditions we will consider free floating inside boundary conditions [7] and harmonic outside temperature with an amplitude of $10^{\circ} \mathrm{C}$, an average temperature of $0^{\circ} \mathrm{C}$ and a period of 24 hours; the inside and outside surface resistances are still neglected.

By replacing the corresponding thermal properties for brick and mortar in equations (3) and (4) we find the equivalent thermal properties $\lambda_{\text {eq }}=0.952 \mathrm{~W} / \mathrm{m} . \mathrm{K}$ and $(\rho c)_{\mathrm{eq}}=1.913 \mathrm{MJ} / \mathrm{m}^{3} \mathrm{~K}$ The results show that for a same external solicitation, the two models give the same temperature variation with a correlation coefficient approximately equal to 1 .

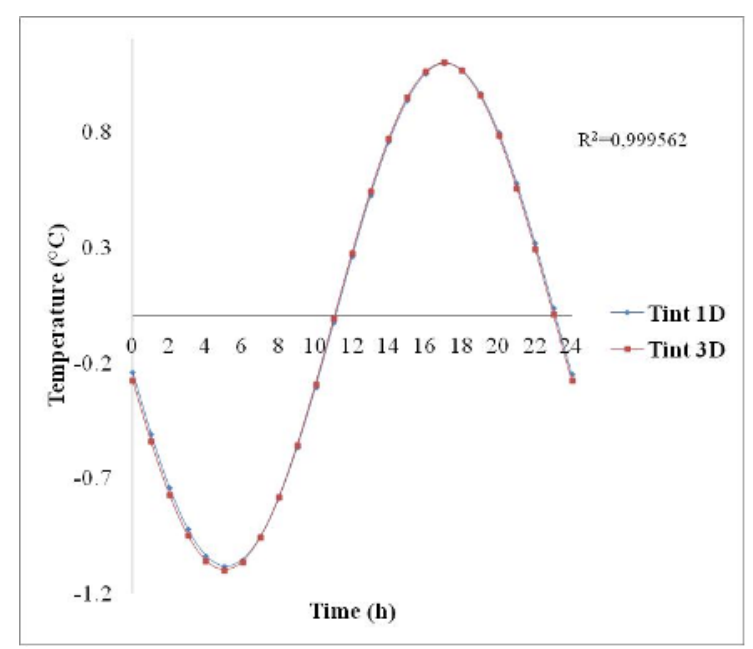

Fig. 3. Adequacy between the $1 \mathrm{D}$ and the $3 \mathrm{D}$ models

\section{The experimental model}


In order to determine the thermal properties of the brick wall studied and to validate the adequacy between theoretical and experimental results, a wall similar to the one modeled was built and submitted to different solicitations. Thermocouples were put at different thicknesses and in two different layers in order to verify that the heat transfer is unidirectional.

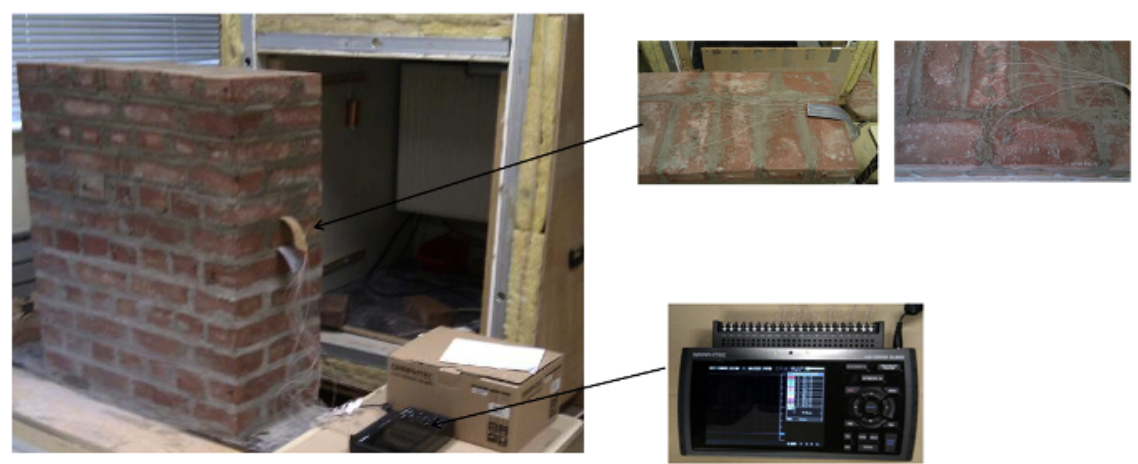

Fig. 4. The experimental model

The wall constitutes one of the four lateral faces of the heating box which contains a radiator with a controlled temperature fluid (figure 4). Two different signal types were programmed for the fluid temperature: the constant signal and the sinusoidal signal: the first one implies a steady-state regime and the second one implies a harmonic regime. These regimes are studied in order to characterize the system and verify the theoretical models utilized for this characterization.

\subsection{The steady-state regime}

We impose constant temperatures of $5,10,15,20,25,30,35,35,40,45,50,55$ and $60^{\circ} \mathrm{C}$ for the heating fluid and await the establishment of steady state in each case. During the steady-state regime there is no heat storage in any component; the electrical analogy leads us then to the following scheme:

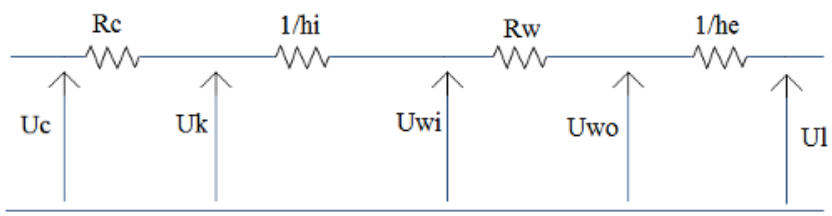

Fig. 5. Electrical analogy for the experimental model in steady-state regime

$$
\begin{gathered}
U_{k}=U_{c}\left(1-\frac{R_{c}}{R_{t}}\right)+\frac{R_{d}}{R_{t}} U_{l} \\
U_{w i}=U_{c}\left(1-\frac{R_{c}+\frac{1}{h_{i}}}{R_{t}}\right)+\frac{R_{c}+h_{i}}{R_{t}} U_{l} \\
U_{w o}=U_{c}\left(1-\frac{R_{c}+\frac{1}{h_{i}}+R_{w}}{R_{t}}\right)+\frac{R_{c}+\frac{1}{h_{i}}+R_{w}}{R_{t}} U_{l}
\end{gathered}
$$


$2^{\text {nd }}$ European Energy Conference

$$
|I|=\left|\frac{U_{c}-U_{l}}{R_{t}}\right|
$$
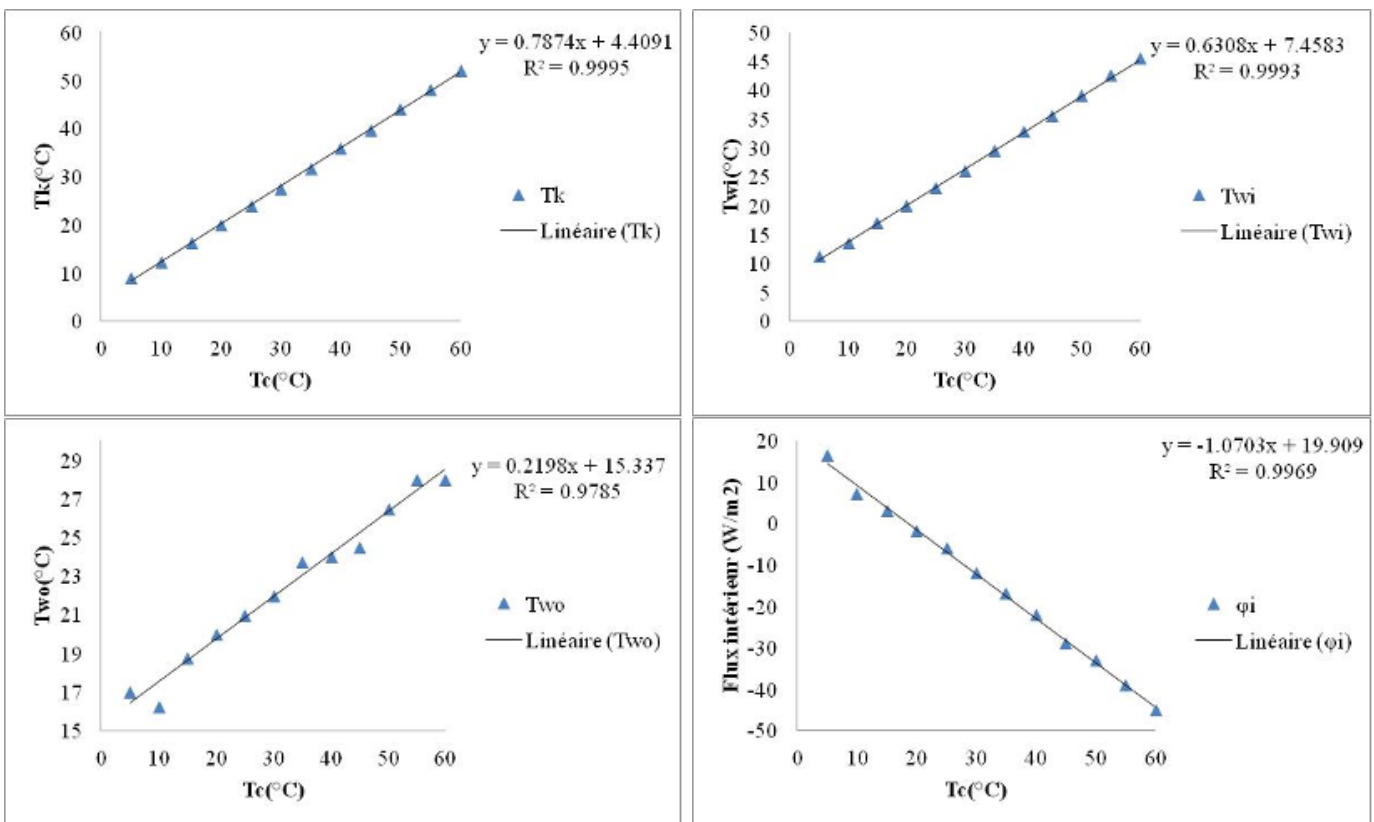

Fig. 6. Variations of the box temperature, the inner wall temperature, the outer wall temperature and the heat flux, with respect to the fluid temperature

The parameters of the system in steady state, i.e. $R_{c}, h_{i}, R_{w}$ and $h_{e}$ are determined by identifying the slope of the obtained lines with the corresponding equations:

$$
\begin{aligned}
& (8) \Rightarrow \frac{1}{R_{t}}=1.0703 \Rightarrow R_{t}=0.9343 \mathrm{~m}^{2} \cdot \mathrm{K} / \mathrm{W} \\
& (5) \Rightarrow 1-\frac{R_{d}}{R_{t}}=0.7874 \Rightarrow R_{d}=0.1986 \mathrm{~m}^{2} \cdot \mathrm{K} / \mathrm{W} \\
& (6) \Rightarrow 1-\frac{R_{d}+\frac{1}{h_{i}}}{R_{t}}=0.6308 \Rightarrow h_{i}=6.833 \mathrm{~W} / \mathrm{m}^{2} \cdot \mathrm{K} \\
& (7) \Rightarrow 1-\frac{R_{d}+\frac{1}{h_{i}}+R_{w}}{R_{t}}=0.2198 \Rightarrow R_{w}=0.3840 \mathrm{~m}^{2} \cdot \mathrm{K} / \mathrm{W} \\
& h_{e}=\frac{1}{R_{t}-R_{d}-\frac{1}{h_{i}}-R_{w}}=4.870 \mathrm{~W} / \mathrm{m}^{2} \cdot \mathrm{K}
\end{aligned}
$$

\subsection{The harmonic regime}


a.) The wall:

We assume the wall subjected from its both sides to sinusoidal excitations whose equations are determined from experimental curves. The resulting temperature of the two sinusoids at an abscissa $\mathrm{x}$ and a time $\mathrm{t}$ is given by [8]:

$$
\begin{aligned}
T(x, t) & =T_{m}(x)+\Delta T_{i} \cdot \sum_{n=0}^{\infty}\left\{\operatorname{Exp}\left[-\left[(2 n+1) \frac{e}{2}+(-1)^{2} \cdot\left(x+\frac{e}{2}\right)\right] \sqrt{\frac{\omega}{2 a}}\right] \cdot \sin \left[\omega t-\left[(2 n+1) \frac{e}{2}+(-1)^{2} \cdot\left(x+\frac{e}{2}\right)\right] \cdot \sqrt{\frac{\omega}{2 a}}\right]\right\} \\
& +\Delta T_{e} \cdot \sum_{n=0}^{\infty}\left\{\operatorname{Exp}\left[-\left[(2 n+1) \frac{e}{2}-(-1)^{n} \cdot\left(x+\frac{e}{2}\right)\right] \sqrt{\frac{\omega}{2 a}}\right] \cdot \sin \left[\omega t-\left[(2 n+1) \frac{e}{2}-(-1)^{n} \cdot\left(x+\frac{e}{2}\right)\right] \cdot \sqrt{\frac{\omega}{2 a}}\right]+\phi\right\}
\end{aligned}
$$
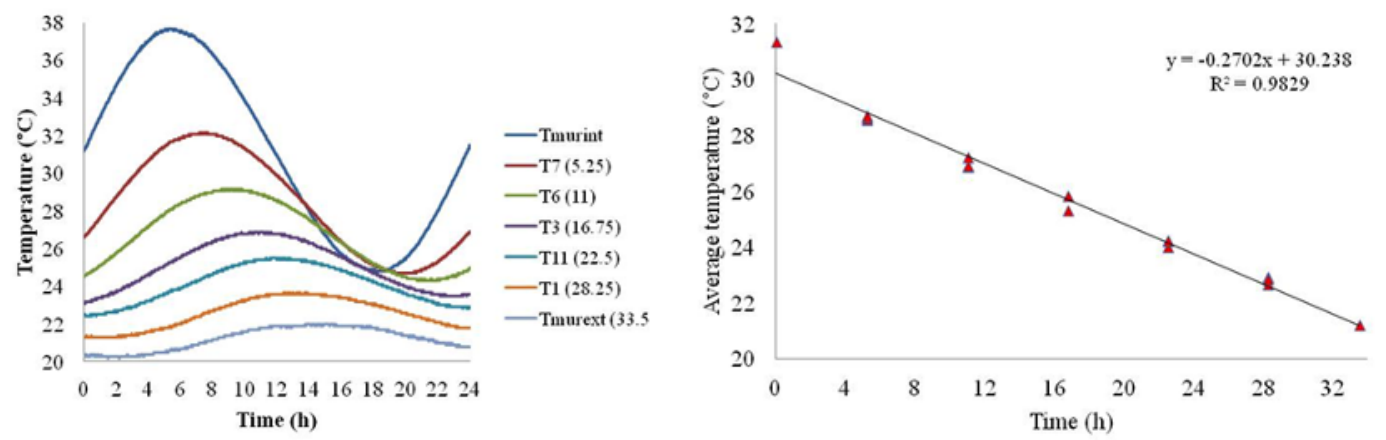

Fig. 7.Temperature variation in harmonic regime for different thicknesses through the wall

Assuming that $f(n)=(2 n+1) \frac{e}{2}+(-1)^{n} \cdot\left(x+\frac{e}{2}\right), g(n)=(2 n+1) \frac{e}{2}-(-1)^{n} \cdot\left(x+\frac{e}{2}\right)$ and $\alpha=\sqrt{\frac{\omega}{2 a}}$, and for $\mathrm{x}=0.11 \mathrm{~m} ; \mathrm{T}(\mathrm{x}, \mathrm{t})=\mathrm{T}_{\mathrm{m}}(\mathrm{x})$ for $\mathrm{t}=3.29 \mathrm{~h}$; equation $(9)$ can be written as:

$$
H(\alpha)=6.55 \sum_{n=0}^{\infty}\{\operatorname{Exp}[-f(n) \cdot \alpha] \sin [0.86-f(n) \cdot \alpha]\}+0.8 . \sum_{n=0}^{\infty}\{\operatorname{Exp}[-g(n) \cdot \alpha] \sin [0.86-g(n) \cdot \alpha-2.28]\}=0
$$

By plotting this function $H(\alpha)$, we can determine $\alpha$ which is the intersection of the curve $H(\alpha)$ with the $\mathrm{x}$-axis. 


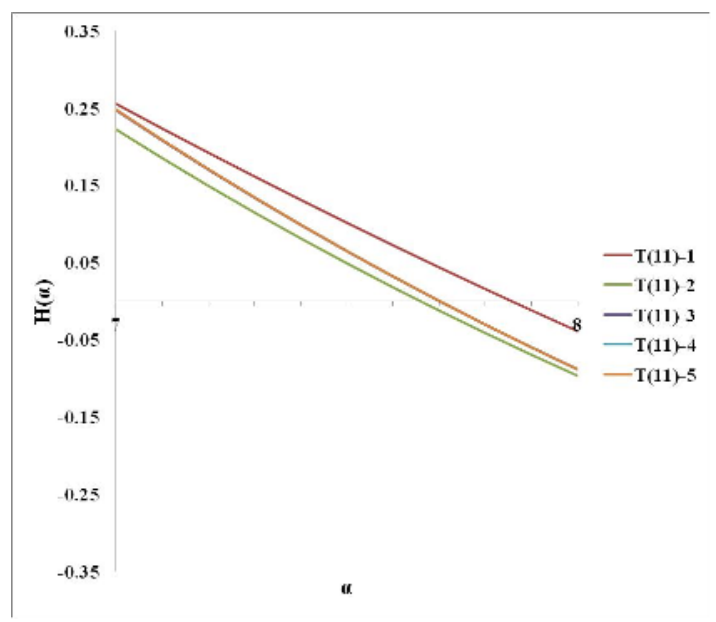

Fig. 8.Temperature variation in harmonic regime for different thicknesses

The solution converges from the third order $(n=3)$. Repeating the same calculation for the other thicknesses $(x=5.25 ; x=16.75 ; x=28.25$ and $x=34 \mathrm{~cm})$ we find $\alpha_{\text {average }} \approx 7.52$; which gives a thermal diffusivity of $a=6.43 \mathrm{E}-7 \mathrm{~m}^{2} / \mathrm{s}$ and then a volumetric heat capacity of $\mathrm{C}_{\text {average }}=1376394 \mathrm{~J} / \mathrm{m}^{3} \mathrm{~K}$.

b.) The damping system:

The heating system with the box constitutes a damping system which produces a phase shift of thermal solicitations and a decrease in their amplitude. We represent this system by following electrical scheme $[9,10]$ :

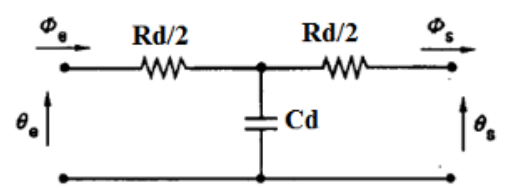

Fig. 9. Electrical representation of the damping system

$R_{d}$ is the thermal resistance of the heating system and the internal convection:

$R_{d}=R_{c}+\frac{1}{h_{i}}=0.345 \mathrm{Km}^{2} / \mathrm{W}$

Assuming the damping system to be as a fictitious wall having a thickness $\mathrm{x}$ and thermal properties $\lambda_{d}, Q_{d}$ and $c_{d}$, we have:

$$
R_{d} C_{d}=\frac{x}{\lambda} x \rho c=\frac{x^{2}}{a}
$$

The time lag $\Psi$ is determined from experimental curves and then we can determine the diffusivity of the equivalent thermal system $[11,12]$

$$
\Psi=x_{i} \sqrt{\frac{\omega}{2 a}} \quad \text { with } \quad \omega=\frac{2 \pi}{T} \Rightarrow a=\left(\frac{x_{i}}{\Psi}\right)^{2} \frac{\omega}{2}
$$

$(10)$ and $(11) \rightarrow \Psi=3,42 \cdot \frac{\pi}{12}=0,895 \Rightarrow R C=\frac{2 \Psi^{2}}{\omega}=22047 \mathrm{~s}$ 


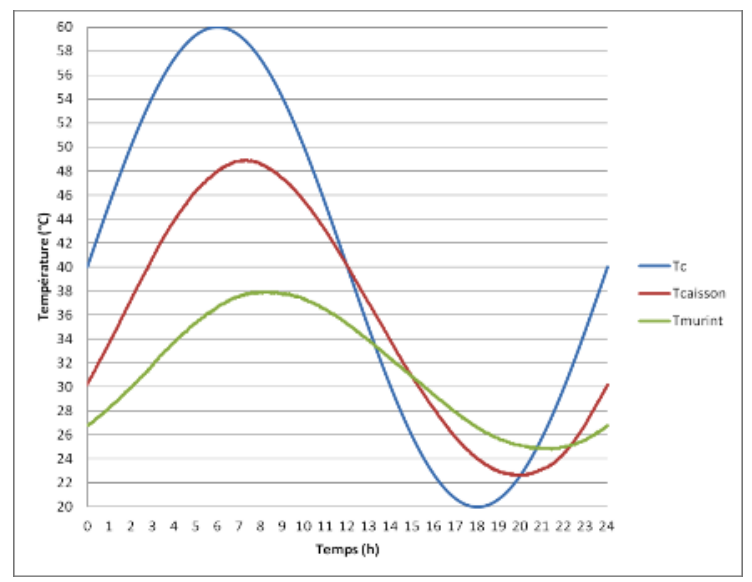

Fig. 10. Temperature variation in harmonic regime for different thicknesses through the wall

Having $R=0.345 \mathrm{~m}^{2} \mathrm{~K} / \mathrm{W}$, equation (11) gives $\mathrm{C}_{\mathrm{d} \text { (surf.) }}=63914 \mathrm{~J} / \mathrm{m}^{2} \mathrm{~K}$

\section{Conclusion and perspectives}

This study contributes to a better understanding of the thermal transfer in brick walls in steadystate and harmonic regimes in order to determine the characteristics of these walls and to propose a suitable insulation material. The experimental device is modeled in the different regimes applied and the thermal properties of the different components of the system are determined in the steady-state and harmonic regime.

The next step will be the application of different insulation materials (traditional and ecological) to the studied brick wall in order to compare these materials with different configuration (insulation from outside/inside) and choose a suitable material for our case.

\section{References}

1. Thierry Thieffry, Study of the housing at Lille, 2008.

2. EDF-CREPAH HLM, Le bâti ancien en Flandre-Artois, 1982.

3. Agence de développement et d'urbanisme lilloise, Morphologie, structure urbaine et typologie de l'habitat, 1993.

4. ATHEBA, Comprendre son comportement thermique, fiche technique, Maison Paysannes de France, 2010.

5. ATHEBA, Comprendre son comportement hygrométrique, fiche technique, Maison Paysannes de France, 2010 .

6. CSTB, Base de données INIES, Logiciel ELODIE

7. C. Luo, B. Moghtaderi, H. Sugo, A. Page "Time Lags and Decrement Factors under Air-Conditioned and Free-Floating conditions for Multi-Layer Materials”, BS 2007 - Beijing, China

8. Y. JANNOT, “Transferts thermiques”, 2009

9. C. Peng, Z. Wu, "Thermoelectricity analogy method for computing the periodic heat transfer in external building envelopes", Applied Energy, volume 85, 2008, p. 735-754 


\section{$2^{\text {nd }}$ European Energy Conference}

10. G. Fraisse, C. Viardot, O. Lafabrie, G. Achard "Development of a simplified and accurate building model based on electrical analogy", Energy and Buildings, volume 34, 2002, p. 1017-1031

11. Ben Bellabah A., Caractérisation de matériaux par phénomènes thermiques transitoires, PhD thesis, Cheikhanta Diop University - Dakar, 1996

12. Ulgen K., «Experimental and theoretical investigation of effects of wall's thermophysical properties on time lag and decrement factor », Energy and Buildings, vol. 34, 2002, p. 273-278

13. Yu J., Yang C., Tian L., Liao D., «A study on optimum insulation thickness of external walls in hot summer and cold winter zone of China », Applied Energy, vol. 86, 2009, p.2520-2529 